Article

\title{
Building a Framework of Evaluating Human-Environment Relationships: Considering the Differences between Subjective Evaluations and Objective Assessments
}

\author{
Ying Liu $1,2, * \mathbb{C}$, Wei Deng ${ }^{1,2,3, *}$ and Li Peng ${ }^{1,2}$ (I) \\ 1 College of Geography and Resources, Sichuan Normal University, Chengdu 610101, China; \\ pengli@imde.ac.cn \\ 2 Institute of Mountain Hazards and Environment, Chinese Academy of Science, Chengdu 610041, China \\ 3 Collage of Resource and Environment, University of Chinese Academy of Science, Beijing 100190, China \\ * Correspondence: liuying@imde.ac.cn (Y.L.); dengwei@imde.ac.cn (W.D.)
}

Received: 19 November 2019; Accepted: 18 December 2019; Published: 24 December 2019

\begin{abstract}
The human-environment relationship is bidirectional, meaning that human attitudes and behavior to nature are at the root of environmental change, while changes in the environment affect human attitudes and behavior. It is necessary to analyze the human-environment relationship from two aspects: (a) Whether there is a good objective basis for maintaining an environment, and (b) whether people report that they are satisfied with that environment. This study attempted to construct a framework to evaluate the human-environment relationship considering these two aspects. The framework consists of three parts: Traditional evaluation, indicator construction, and evaluation considering the relationship between subjective and objective assessment. Traditional evaluations consist of subjective evaluations and objective assessments. Indicator construction focuses on putting forward indicators that quantitively evaluate the human-environment relationship, considering the results of objective assessments and subjective evaluations. The indicators introduced in this study include MD (match degree) and OSC (objective assessment and subjective evaluation comparison) to explain the difference and the relationship between objective assessments and subjective evaluations of the environment. Then, based on the indicator value, a matrix containing four situations (Match- $\mathrm{H}$, Match-L, H-L, and L-H) was constructed to explore why a human-environment relationship may not be harmonious. Since the upper Minjiang River basin is a typical area, because of its intensive human activity, as well as its fragile ecological environment, this study chose it as a case study and used it to verify the framework. Through the framework construction and application, this study found that: (1) The framework of this study provided a more comprehensive method to evaluate the human-environment relationship; (2) as the subjective evaluation was based on individual comprehensive tradeoffs, the evaluation combining the subjective and objective assessment was more accurate; (3) environmental conditions were the basis, and human activities were the key factors, for the coordination of human-environment relationships; so the matrix put forward in this study was necessary for finding the cause of human-environment incongruity.
\end{abstract}

Keywords: human-environment relationship; indicator; environment-oriented approach; subject-oriented approach 


\section{Introduction}

A substantial body of literature has been published examining the human-environment relationship. In these studies, the human-environment relationship was evaluated from at least two different perspectives: Object-based assessment and subject-based evaluation.

Object-based assessment focuses on the relationship between an ecological system and a human societal system, considering in particular the relationship between intensity of development and ecological vulnerability. Traditional analysis includes index evaluation, as well as a spatial analysis. Index evaluation mainly uses a method of constructing an index system that includes the social economic index and the resource environment index. Gao Chao et al. evaluated human-environment systems through evaluating the vulnerability of eco-environment systems, economic systems, and social systems, separately, using the vulnerability indicator system [1]. Spatial analysis was conducted based on mapping GIS, with focus on spatial exploration of social-ecological systems. Alessa et al. identified social-ecological "hotspots" using mapping GIS [2]. Hamannet al. presented an approach to mapping social-ecological systems based on bundles of direct ES use [3].

Subject-based evaluation was mainly carried out from the perspective of environmental psychology, mostly related to environmental attitudes and behavior, such as environmental identity [4-6], connectedness to nature [7-9], and commitment to the environment. Based on the hypothesis that a positive attitude to the environment is an important factor for pro-environmental behavior, and that pro-environmental behavior is beneficial for human-environment congruity [10], a large number of studies have focused on analyzing whether different environmental attitudes are related to varied environmental behavior. Hinds and Sparks reported that affective connection is a significant independent predictor of intention to engage with the natural environment [6]. Whitmarsh and $\mathrm{O}^{\prime}$ Neill put forward that pro-environmental self-identity was a significant predictor for certain pro-environmental behavior [11]. Davi et al. explained how commitment to the environment predicted general ecological behavior and willingness to make sacrifices for the environment [12].

The human-environment relationship is bidirectional, meaning that human attitudes and behavior to nature are at the root of environmental change [13], while changes in the environment affect human attitudes and behavior. Paul M Muchinsky reported that there are two types of human-environment congruence: Supplementary and complementary. Supplementary congruence is the connection between an individual and a group of people who comprise an environment. Complementary congruence is the match between an individual's talents and the corresponding needs of the environment [14]. As a result, more and more scholars have put forward that it is necessary to analyze the human-environment relationship from two aspects: (a) Whether there is a good objective basis for maintaining an environment, and (b) whether people report that they are satisfied with that environment $[15,16]$. The former is referred to as "objective" because it involves general measures of the qualities of the environment, while the latter is referred to as "subjective" because it relies on self-reporting tools through which a person expresses their own observations and evaluations $[17,18]$. While scholars have realized the importance of combining subjective cognition and objective bases for the study of the human-environment relationship, research proposing methods of evaluating the human-environment relationship that consider the relationship between subjective evaluation and objective assessment was lacking. Gabriel Moser proposed a framework for connecting objective assessments of an environment and subjective expressions of individual feelings. The framework provides a matrix containing four situations: (1) Good objective conditions with environmental satisfaction; (2) good objective conditions with environmental dissatisfaction; (3) bad objective conditions with environmental satisfaction; and (4) bad objective conditions with environmental dissatisfaction [18]. Ilaria Rodella chose five parameters to compare the physical and social assessments of selected beaches and integrated the CSES and UP parameters through sector analysis, modifying the sectorial table proposed by Rangel-Buitragoetal and Williamsetal [19].

Considering all the above, this article tried to answer three questions: (1) Whether, in addition to the theoretical framework, we can put forward a method to quantitively evaluate the human-environment 
relationship considering the results of objective assessments and subjective evaluations; (2) whether we can apply an indicator to quantify the difference between objective assessments and subjective evaluations; and (3) how we can identify the reason human-environment relationships are incongruent.

Based on the target stated above, the article was organized as follows. Section 2 introduces the framework development. Section 3 presents the application of the framework. Section 4 gives a discussion about the framework while Section 5 draws some conclusions.

\section{Framework Development}

The framework consists of three parts (Figure 1), including traditional evaluation, indicator construction, and evaluation considering the relationship between the subjective and objective assessment. Traditional evaluations consist of a subjective evaluation and objective assessment. Indicator development focuses on proposing indicators that quantitively evaluate the human-environment relationship considering the results of objective assessment and subjective evaluation. Evaluations considering the relationship between subjective and objective assessment attempts to qualitatively analyze the human-environment relationship, as well as give the suggestion of coordinating human-environment relationship according to the results of indicator calculation and comparison among regional characters. The first two parts were inclined to quantitative analysis, and the third part was inclined to qualitative analysis.

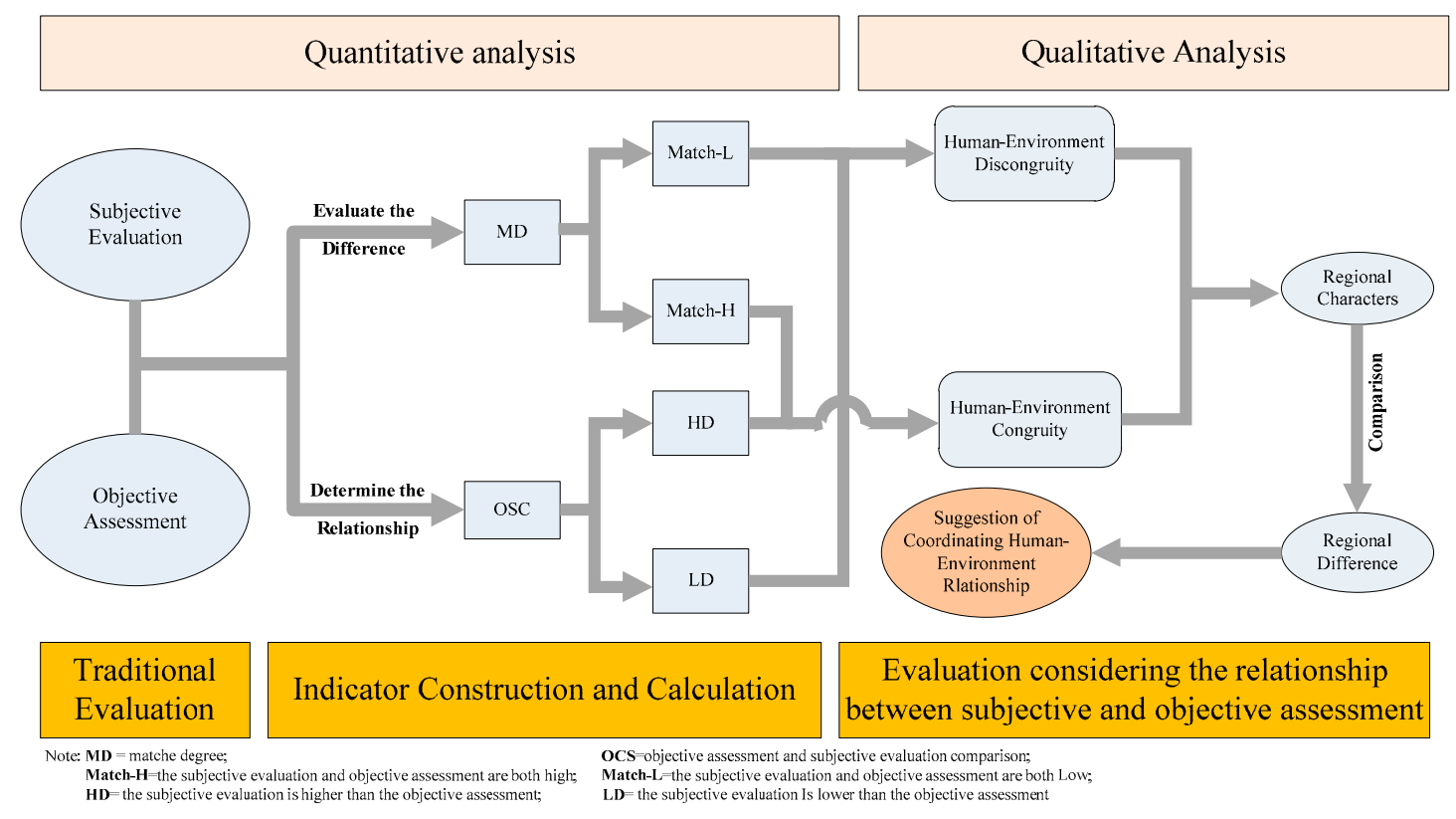

Figure 1. Framework of human-environment relationship evaluation.

\subsection{Traditional Evaluation}

\subsubsection{Objective Evaluation}

The objective evaluation included three parts: The first was an evaluation of the comprehensive intensity of human activity; the second was an evaluation of natural ecosystem vulnerability; and the third was an evaluation of human-environment relationship in villages. The first and second parts were based on the raster data and analyzed from a geographical space, the third part was based on the results of the first two and analyzed from an administrative space (Figure 2). 


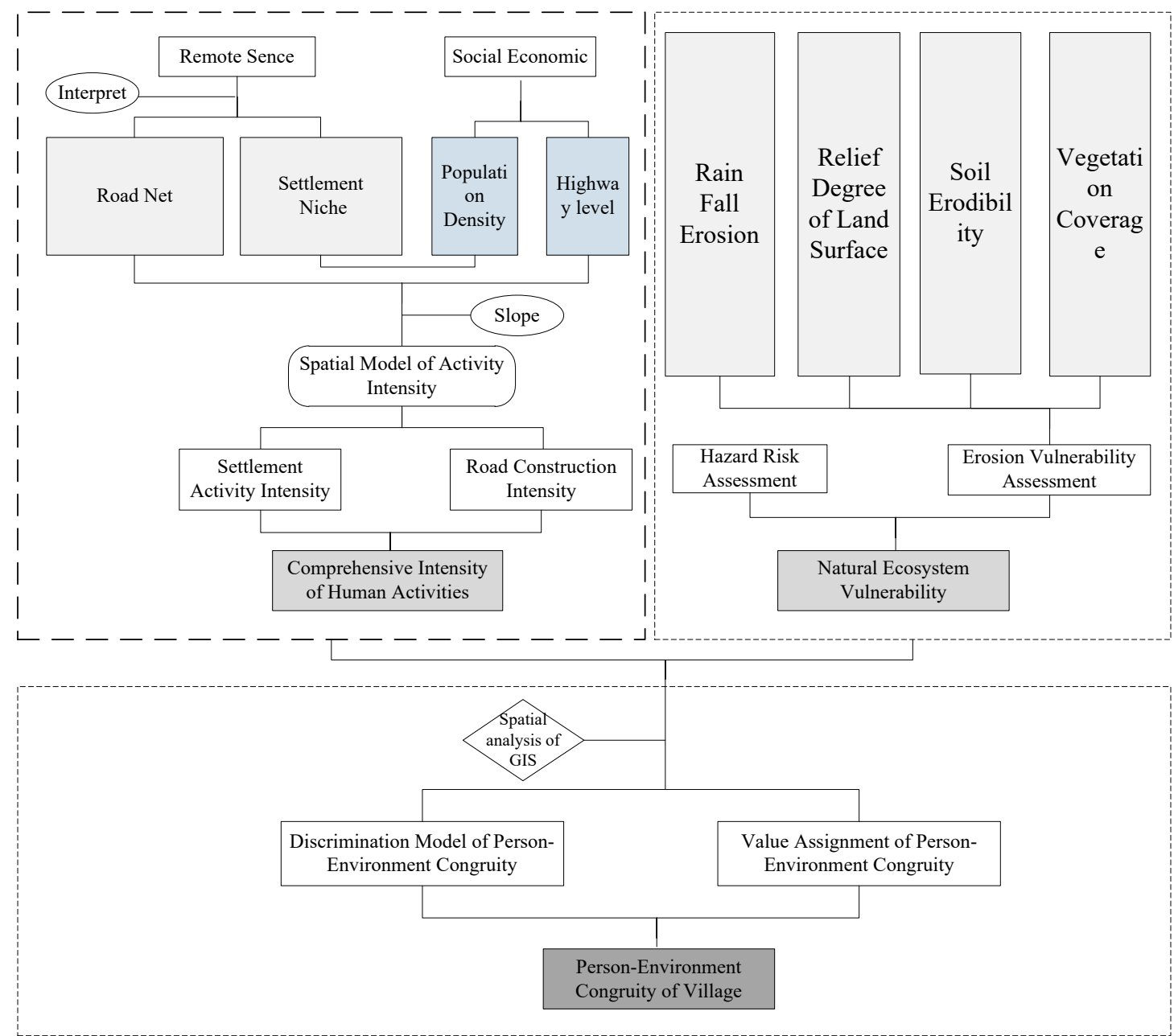

Figure 2. Process of objective evaluation.

(1) Evaluation of Comprehensive Intensity of Human Activity

With the help of GIS spatial analysis, comprehensive intensity was analyzed, including settlement activity intensity and road construction intensity.

Human activity intensity varied significantly with the degree of population agglomeration, so settlement population density was taken as the basic value of human activity intensity of the settlement center grid I; i.e., source intensity. The source intensity was calculated as follows.

$$
M_{n}=\left(P_{i} \times v_{i j} / V_{i}\right) / A_{i j}
$$

where $M_{n}$ is the source intensity of the settlement center grid in village $i, P_{i}$ is the total population of village $i, v_{i j}$ is the residential area of settlement $\mathrm{j}$ in village $i$, and $V_{i}$ is the total residential area of village $i, A_{i j}$ is the total area of settlement $j$ in village $i$. After calculating the source intensity of the center grid in different settlements, the settlement intensity was calculated as follows:

$$
I S_{m}=M_{n}-S \times \ln R
$$

where $I S_{m}$ is the human activity intensity of grid point $m$ whose distance from the settlement center grid $\mathrm{n}$ is $R, M_{n}$ is the source intensity of the settlement center grid $\mathrm{n}$, and $S$ is the slope correction factor (the greater the slope, the greater the resistance to human activity intensity spread, so we set $25^{\circ}$ as a 
threshold; when the slope is more than $25^{\circ}$, the settlement activity is no longer spreading). $R$ is the distance from grid point $n$ to grid point $m$.

Expert scoring methods and the analytic hierarchy process (AHP) were used to determine the source intensity of roads of different grades $\left(I R_{m}\right)$, which was taken as the intensity value of the grid of the road center point. Considering the road distance attenuation effect of radiation to the surrounding areas, as well as the impact of topography on radiation limits, and using the inverse distance weighting method (IDW), with the slope as a limiting factor for spatial interpolation, when the slope is greater than $25^{\circ}$, the strength value is 0 .

After calculating the settlement activity intensity and road construction intensity, using overlay analysis in GIS, the comprehensive intensity of human activity was calculated.

$$
I_{m}=W_{s} I S_{m}+W_{R} I R_{m}
$$

where $I_{m}$ is the comprehensive intensity of human activity of grid $\mathrm{m}, W s$ and $W_{R}$ is the weight of settlement activity intensity and road construction intensity, $I S_{m}$ is the settlement activity intensity of grid point $\mathrm{m}$, and $I R_{m}$ is the road construction activity intensity of grid point $\mathrm{m}$.

Finally, based on the result, the layer of comprehensive intensity of human activity was divided into four levels, where 'level $1^{\prime}$ meant human activity was low and 'level $4^{\prime}$ meant human activity was high.

\section{(2) Evaluation of Natural Ecosystem Vulnerability}

Considering the erosion risk and disaster risk, the natural ecosystem vulnerability was calculated.

Firstly, considering rainfall erosion, relief degree of land surface, soil erodibility, and vegetation coverage, as well as the soil erosion situation, the erosion risk were obtained. The result was divided into three levels, including low, general, and high, through the natural fracture method in GIS. Then, using overlay analysis in GIS, the erosion risk layer and disaster risk layer was overlaid and, according to the discriminant standard (Table 1), the natural ecosystem vulnerability was calculated.

Table 1. Discriminant standard of natural ecosystem vulnerability evaluation.

\begin{tabular}{cccc}
\hline Erosion Risk & Low & General & High \\
\hline Disaster Risk & & & General \\
Low & Low & low & High \\
General & Low & General & High \\
\hline
\end{tabular}

\section{(3) Evaluation of Human-Environment Congruity of Villages}

Based on the result of the evaluation of the comprehensive intensity of human activity and natural ecosystem vulnerability, the human-environment congruity of geographical space was obtained using the overlay method. Focus group discussions (FGD) were conducted in order to determine the discrimination model of human-environment congruity (Table 2). The focus group consisted of sixteen experts from the Chinese Academy of Sciences, Yunnan University, Sichuan University and Sichuan Normal University. Experts debated the issue that human activities and environment conditions, which had a greater impact on the human-environment relationship. Through discussion, most of the experts thought human activities had a slightly larger impact on human-environment relationship, so the discrimination model first focuses on human activity intensity, and then integrated the environment conditions. Based on the conclusion, this study divided human-environment congruity into five categories, including excessive area, antagonism area, background area, balanced area, and harmonious area. 
Table 2. Discrimination model of human-environment congruity.

\begin{tabular}{ccccc}
\hline \multicolumn{1}{c}{ Human Activity } & & & & \\
The Fragility of Natural Ecosystems & Lowest & Low & General & High \\
\cline { 1 - 3 } Low & & & & \\
General & Balance & Balance & Harmonious & Harmonious \\
High & Background & Background & Antagonism & Antagonism \\
Excessive & Excessive \\
\hline
\end{tabular}

Excessive area means intense human activity within a fragile ecological environment; antagonism area means the human activity was generally high while the ecological environment was generally fragile. The areas with low human activity and fragile ecological environment were divided into the background area, while balanced area included the areas with low human activity and a healthy ecological environment; harmonious area means human activity was intense in the area but the ecological environment was not fragile.

As we focus on the human-environment congruity of villages, the value assignment of different categories is necessary in order to obtain the human-environment congruity of administrative space. Through the focus group discussions (FGD), the value assignment was determined (Table 3) and the human-environment congruity of different villages is calculated. Using spatial analysis in GIS, including the natural fracture method, the village was divided into five categories: The higher the value, the more harmonious the human-environment congruity.

Table 3. Assignment of human-environment congruity.

\begin{tabular}{cccccc}
\hline Category & Excessive & Antagonism Background & Balance & Harmonious \\
\hline Value & 0 & 1 & 2 & 3 & 4 \\
\hline
\end{tabular}

\subsubsection{Subjective Evaluation}

The data of subjective evaluation was acquired from the questionnaire. We hypothesized that cognition on a single environment (such as air condition, water condition, etc.) affected cognition on the overall environment; the findings of our investigation supported this hypothesis. Therefore, in addition to the demographic questions, the questionnaire included two components that refer to environment cognition. One was focused on a single environment and the other on the comprehensive perception. Most of the questions were closed questions. These questions were developed to measure attitudes to the environment on a three-point scale from 'well' to 'bad' (e.g., What do you think of the situation of vegetation and the change of vegetation? What do you think of the living environment in this village? What do you think of the effect of human activity on the environment, such as farming, industry, road construction, or tourism development?)

Meanwhile, a small number of questions were semi-closed questions to get more information from these questions (e.g., How is the environment changing, for better or worse? What causes this change? Do you think the environment was suitable for living and why?)

The subjective evaluation model was based on closed questions and, through the focus group discussions, the AHP method was used to determine the weight of two components, as well as different factors were determined. The model was as follows:

$$
\mathrm{HEC}_{\mathrm{S} \_\mathrm{E}}=W_{1} \sum_{i=1}^{n} w_{i} x_{i}+W_{2} \sum_{j=1}^{m} w_{j} x_{j}
$$

where $\mathrm{HEC}_{\mathrm{S}_{-} \mathrm{E}}$ means the subjective evaluation of human-environment congruity; $W_{1}$ and $W_{2}$ were the weight of two components; $w_{i}$ was the weight of $x_{i}$ in component 1 and $x i$ was the factor about the cognition of a single environmental component, such as air condition, land quality, etc., in component $1 ; w_{j}$ was the weight of $x_{j}$ in component 2 and $x_{j}$ was the factor on comprehensive perception and 
attitude to the comprehensive environment in component 2 . The higher the value of $\mathrm{HEC}_{\mathrm{S}_{-} \mathrm{E}}$ was, the more harmonious the human-environment congruity. This study then divided the HEC $\mathrm{C}_{\text {-E }}$ into three categories including harmonious, general, and inferior. The percentages of different categories were calculated; the category with the highest proportion is the result of a subjective evaluation of the village.

\subsection{Indicator Construction and Calculation}

In order to combine the objective assessment and subjective evaluation, this study put forward two indicators including match degree (MD), objective assessment and subjective evaluation comparison (OSC) which included two sub-indices higher degree (HD) and lower degree (LD). MD was used to evaluate the difference between the objective assessment and subjective evaluation. The value of MD was higher; the difference between the object assessment and subjective evaluation was smaller. OSC was used to determine the relationship between objective assessment and subjective evaluation. For quantitative evaluation, this study provided the calculation model of MD, HD, and LD.

$$
\begin{aligned}
& \mathrm{MD}=\frac{N_{s}}{T} \\
& \mathrm{HD}=\frac{N_{h}}{T} \\
& \mathrm{LD}=\frac{N_{l}}{T}
\end{aligned}
$$

where MD meant the match degree, HD meant the higher degree, and LD meant the lower degree; $N_{S}$ was the number of households where the subjective evaluation was the same with the objective evaluation (i.e., in the objective evaluation, the village belongs to the general level and in the subjective evaluation, the household thinks the village belongs to the general level), $N_{h}$ was the number of households that the subjective evaluation was higher than the objective evaluation (i.e., in the subjective evaluation, the household thinks the village belongs to the harmonious level while the village was inferior in the objective evaluation), $N_{l}$ was the number of households where the subjective evaluation was lower than the objective evaluation (i.e., in the subjective evaluation, the household thinks the village belongs to the inferior level while the village belongs to the general level in the objective evaluation); $\mathrm{T}$ was the total number of households in the village.

\subsection{Evaluation Considering the Relationship between Subjective and Objective Assessment}

In addition to quantitively evaluation, a matrix was then constructed. It included four situations (Table 4).

Table 4. Matrix of comparison between subjective evaluations and objective assessment.

\begin{tabular}{ccc}
\hline Sub-Evaluation & High & Low \\
Obj-Assessment & & Match-H \\
High & H-L & Match-L \\
\hline
\end{tabular}

Through the matrix, the human-environment relationship could be evaluated. The H-L or Match-H areas were human-environment congruous area, while the L-H or Match- $\mathrm{L}$ areas were human-environment incongruous areas. Based on the comparison between the regional characteristics of human-environment congruous areas and human-environment incongruous areas, regional differences were obtained. Additionally, based on it, the suggestion of coordinating human-environment was provided. 


\section{Application of the Framework}

\subsection{Study Area}

The Upper Minjiang River basin refers to the reaches above Dujiangyan. Areas covered by the tributaries include the Wenchuan County, Mao County, Li County, Songpan County, Heishui County. It is located in the northwest Sichuan Basin, east of the Aba Tibetan autonomous Prefecture, east of the Qinghai-Tibet Plateau, and on the east margin of the Hengduan Mountain. It is located at $30^{\circ} 45^{\prime} \sim 33^{\circ} 09^{\prime}$ $\mathrm{N}$ and $102^{\circ} 35^{\prime} \sim 103^{\circ} 56^{\prime}$ E. The upper Minjiang River basin covers an area of approximately $24,000 \mathrm{~km}^{2}$.

The Upper Minjiang River basin is a key area of the upper reaches of the Yangtze River; it features complex geological conditions, abundant resources, and species diversity. The ethnic composition and economic development are very typical, not only effectively reflected in the development characteristics of the upper reaches of the Yangtze River, but also as an important epitome of the development of mountainous areas in China. For these reasons, we chose The Upper Minjiang River basin as our study area.

Furthermore, based on the sixth census of China (2010), the total population in the upper Minjiang River basin is 385,200 [20], with major population distribution in river valleys and mountain terraces. With the advantages of transportation and location, Wenchuan County and Maoxian County gather more than half of the total population of the upper Minjiang River basin, with the population in Li County the smallest. Meanwhile, the topographic conditions and ecological vulnerability in these three counties were more complex. We chose villages in these three counties as sample villages.

Based on objective evaluation of human-environment congruity, villages were divided into five levels by the natural fracture method of ARCGIS (Table 5), the classification criteria were as follows: (I) 0-1.72, (II) 1.72-2.13, (III) 2.13-2.58, (IV) 2.58-3.26, (V) 3.26-4.86. Next, the random sampling method was used to select typical sample villages with different human-environment congruity. Due to the large difference in the number of villages in each level, unequal proportion random sampling was selected, with each level set to extract a number according to the total number. Finally, we chose 12 villages as sample villages (Figure 3, Table 6).

Table 5. The value of human-environment congruent of village.

\begin{tabular}{cccccc}
\hline Name & Value & Name & Value & Name & Value \\
\hline YGM4 & 3.17 & GK1 & 1.56 & NZ1 & 1.69 \\
XMX4 & 3.25 & QD2 & 2.12 & SL5 & 3.45 \\
JZ5 & 3.55 & MT1 & 1.72 & WMG2 & 1.93 \\
MK3 & 2.52 & AX3 & 2.54 & HTG2 & 1.91 \\
\hline
\end{tabular}

Table 6. The characteristics of sample village.

\begin{tabular}{cc}
\hline Village Name & Characters \\
\hline YGM & Nearby factory \\
XMX & Nearby factory, located at the debris flow gully \\
JZ & Agriculture (vegetable) and tourism \\
MK & Agriculture (fruit trees) and tourism \\
GK & The relocation village \\
QD & The relocation village, Tourism \\
MT & Tourism \\
AX & Agriculture (fruit trees), Nearby wetland park \\
NZ & near by the town of Mao County \\
SL & Agriculture (vegetable) \\
WMG & Agriculture (vegetable), near by the project of railway construction \\
HTG & Agriculture (vegetable), near by the project of railway construction \\
\hline
\end{tabular}




\subsection{Data Source}

\subsubsection{Spatial Data and Procedure}

The spatial data used in this study included spot-5 image data (Panchromatic resolution ratio of $5 \mathrm{~m}, 2013)$, DEM. We utilized remote sensing images in Google Earth for supplementing data (Spot 5 and Spot 4 images, $10 \mathrm{~m}$; 2013). Furthermore, we used the vector data of disaster distribution (2013), hazard risk data, soil erosion data, and NDVI data of the upper Minjiang River basin.

Based on the Spot-5 image data and remote sensing images in Google Earth, the rural settlements and roads were interpreted; these data were used to analyze human activity intensity. Based on the DEM data, the relief degree of the land surface was calculated and used for analyzing the natural ecosystem's vulnerability.

\subsubsection{Investigation Data and Procedure}

There were four field investigations from 2013 to 2016. The first investigation started on 17 November 2013 in Wenchuan County and ended on December 8th, in Songpan County. During this investigation, we focused on getting an overall understanding of the upper Minjiang River basin and getting information from the governments of different county. The second field work period started on 28 July to 13 August 2014, checking the results of our visual interpretation of the settlements in this investigation. The third investigation ranged from 28 July to 5 August 2016, looking at the objective evaluation of human-environment congruity and choosing sample villages for further investigation. The last field investigation was from 28 August to 4 September 2016 when, based on the sample village choice, we finished the questionnaire survey and deep interviews with the village chief and villagers. Through these field investigations, we not only got a clear understanding of the whole situation in the upper Minjiang River basin, but also the problems in the upper Minjiang River basin.

During the questionnaire survey, all participants received a four-page questionnaire concerning personal characteristics and their perceptions and attitudes to the natural environment.

To gain a better understanding from interviewees, we interviewed them one to one. If the interviewee did not understand the question, we explained it to them. Interviewers asked questions at random and the questions could be mutually corroborating, so that we could check whether the answer was true. Finally, 319 questionnaires were issued and 301 were returned. Participants in the investigation were broadly demographically representative of the population sampled (Table 7).

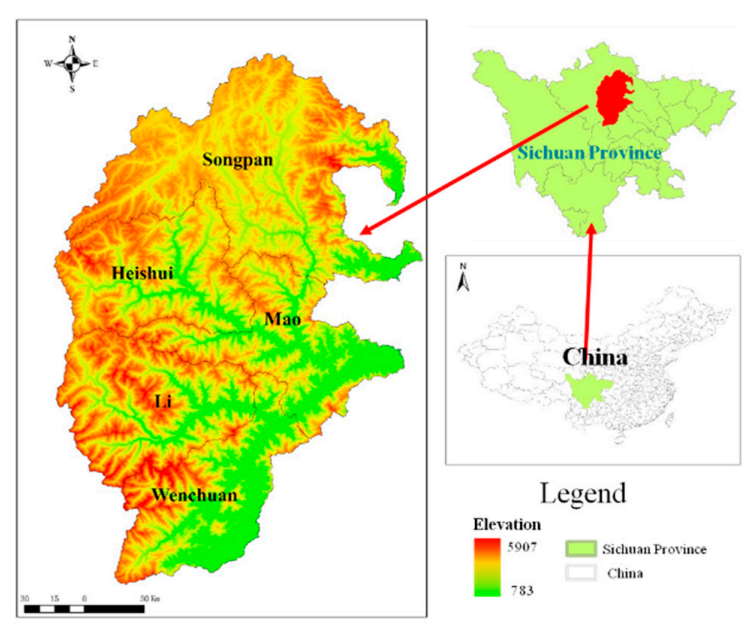

Figure 3. Location of the study area and sample villages.

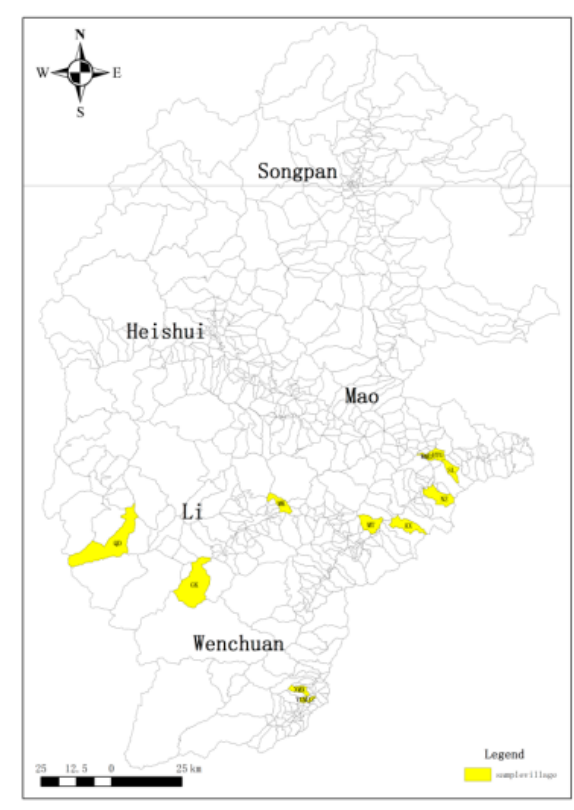


Table 7. Statistics on the participants.

\begin{tabular}{|c|c|c|c|c|c|c|c|}
\hline Variables & Category & Amount & Percentage (\%) & Variables & Category & Amount & Percentage $(\%)$ \\
\hline \multirow{2}{*}{ Sex } & Male & 167 & 55.48 & \multirow{7}{*}{ Household Income } & None & 7 & 2.33 \\
\hline & Female & 134 & 44.52 & & Up to 5000 & 43 & 14.29 \\
\hline \multirow{5}{*}{ Age } & $18-25$ & 22 & 7.31 & & $5001-10,000$ & 39 & 12.96 \\
\hline & $26-40$ & 80 & 26.58 & & $10,001-20,000$ & 66 & 21.93 \\
\hline & $41-50$ & 78 & 25.91 & & $20,001-30,000$ & 55 & 18.27 \\
\hline & $51-60$ & 49 & 16.28 & & $30,001-50,000$ & 54 & 17.94 \\
\hline & 61 and over & 72 & 23.92 & & $50,001-100,000$ & 28 & 9.30 \\
\hline \multirow{4}{*}{ Ethnic } & Han & 70 & 23.26 & \multirow{9}{*}{ Source of Income } & Higher than 100,000 & 9 & 2.99 \\
\hline & Qiang & 178 & 59.14 & & Farming & 170 & 56.48 \\
\hline & Zang & 52 & 17.28 & & By-business & 5 & 1.66 \\
\hline & Hui & 1 & 0.33 & & \multirow{5}{*}{$\begin{array}{l}\text { Individual Business } \\
\text { Operation }\end{array}$} & \multirow{3}{*}{85} & \multirow{3}{*}{28.24} \\
\hline \multirow{5}{*}{ Education } & Primary School and Below & 177 & 58.80 & & & & \\
\hline & Junior High School & 89 & 29.57 & & & & \\
\hline & Senior High School & 24 & 7.97 & & & 17 & 5.65 \\
\hline & Junior College & 7 & 2.33 & & & & \\
\hline & Undergraduate College and Above & 4 & 1.33 & & Other & 24 & 7.97 \\
\hline
\end{tabular}




\subsection{Results}

\subsubsection{The Objective Evaluation}

Through the objective evaluation, the spatial differences of human-environment congruity were obvious. There were 215 villages with a high value (2.59-4.86) of human-environment congruity, accounting for $35.54 \%$ of the total villages. Most of these villages were located in the north of the upper Minjiang River basin, including Songpan County and Heishui County. There were 253 villages with a low value (0-2.12) of human-environment congruity, accounting for $41.82 \%$ of the total villages. Most of these villages were distributed in the south of the upper Minjiang River basin, such as Wenchuan County, Li County, and Mao County

The univariate Moran's I analysis gave a Moran's value of 0.52, meaning the human-environment congruity of the upper Minjiang River basin was positively spatially correlated. According to Moran's scatter plot (Figure 4), the main cluster type was high-high cluster (a village with high value of human-environment congruity was surrounded by villages also having a high value of human-environment congruity) and low-low cluster. There were 205 and 280 villages belonging to first quartile and the fourth quartile, respectively, accounting for $33.89 \%$ and $46.28 \%$ of the total villages. There were only 72 and 48 villages belonging to the second quartile (low-high cluster) and the fourth quartile (high-low cluster), accounting for $11.9 \%$ and $7.93 \%$, respectively.
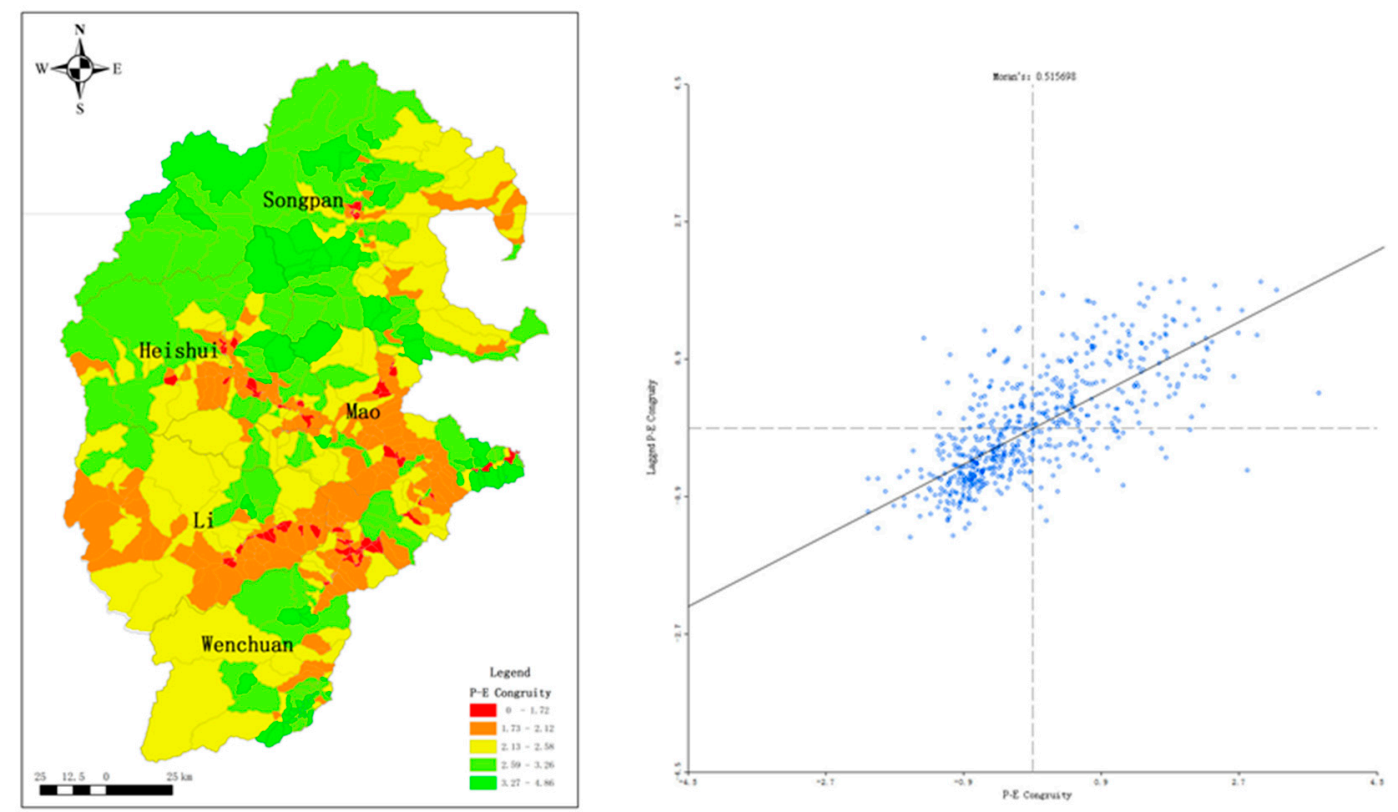

Figure 4. Result of object human-environment congruity and Moran's I.

The local Moran's I analysis revealed exactly where the cluster was. Through the analysis, the 'hot spots' (i.e., areas with a high value of human-environment congruity) of were mainly concentrated in Songpan County and the south of Wenchuan County, while the 'cold spots' (i.e., areas with a low value of human-environment congruity) were mainly located in the contiguous area between Wenchuan County, Mao County, and Li County.

\subsubsection{The Subjective Evaluation}

According to the subjective evaluation (Figure 5), the 12 villages were divided into four categories. MK, NZ, and SL were the first category. The percentage of harmonious was highest in these villages, accounting for $68.18 \%, 52.78 \%$, and $52.17 \%$, respectively, all exceeding $50 \%$. JZ, QD, GK, and AX were in the second category. The proportion of different types (harmonious, general, and inferior) was equally 
distributed in these villages, all around 30\%. MT was the third category. The percentage of 'general' was highest (more than 50\%) while 'inferior' was lowest (around 10\%). YGM, HTG, XMX, and WMG were the fourth category. In contrast to the first category, the percentage of inferior was highest in these villages, accounting for $70.83 \%, 90.47 \%, 79.17 \%$, and $57.14 \%$, respectively, all exceeding $50 \%$.

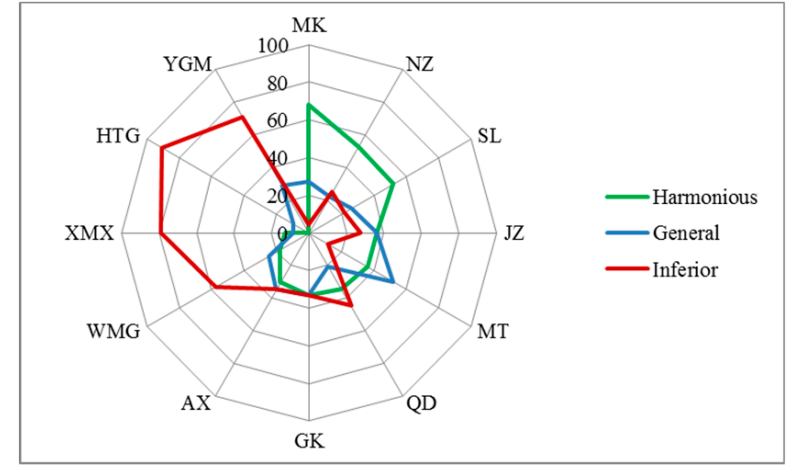

Figure 5. Results of subjective evaluation.

\subsubsection{The Results of MD and OSC}

According to the MD (match degree) value (Figure 6), HTG village was highest, with a value of 0.9 , while YGM village was lowest with a value of 0 . There were three villages in which the MD was higher than 0.5. Six villages had a MD between 0.2 and 0.5. Three villages had a MD less than 0.2. One village belonged to Match-H (SL village) and two villages belonged to Match-L (HTG village and YGM village).
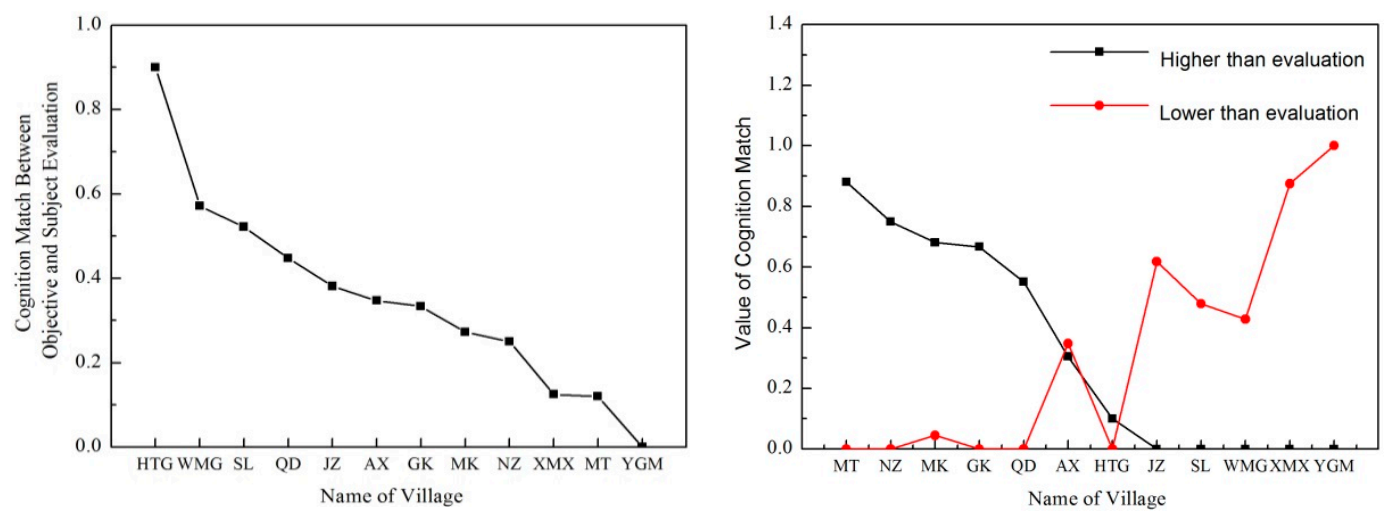

Figure 6. Results of MD (match degree) and OSC (objective assessment and subjective evaluation comparison).

According to the OSC value (Figure 6), the HD (higher degree) and LD (lower degree) was calculated. The HD value of MT, NZ, MK, GK, and QD village was high, meaning that the villagers thought the human-environment relationship is better than the actual situation (from the objective evaluation). The HD value of MT was highest and the value was 0.88 . The value of NZ, MK, GK, and QD were $0.75,0.68,0.67$, and 0.55 , respectively. The LD value of the YGM, XMX, JZ villages was high, meaning the villagers thought the human-environment relationship is worse than the actual situation (objective evaluation). The LD value of YGM was highest with a value of 1 . The LD value of XMX and JZ was 0.875 and 0.619 . The LD value of SL and WMG were 0.47 and 0.42 . The HD value and $L D$ value was equal in the AX village (around 0.3). According to the $H D$ value and $L D$ value, three villages belonged to L-H (YGM, XMX, JZ village) and two villages belonged to H-L (MT, NZ, MK, GK, QD village). 


\section{Discussion}

\subsection{The Framework of this Study Provided a More Comprehensive Method to Evaluate the Human-Environment Relationship}

The purposes of the objective evaluation and subjective evaluation were different. The objective evaluation focuses on the problem of finding or judging the suitability of human activities, while the subjective evaluation was more helpful to understanding the state of the human-environment relationship during the process of development. Furthermore, in addition to the environment itself, subjective cognition was very important; this was helpful for searching for annoyance explanations in a wider stimulus context [21]. Therefore, combining the objective and subjective evaluation was important to examining the human-environment relationship and was helpful for finding areas where the human-environment relationship needs to be adjusted. Therefore, the framework of this study provided a more comprehensive method to evaluate the human-environment relationship.

There were three situations needing special attention. The first indicator was Match-L, it meant that the region was not suitable for human activity from the objective aspect and the subjective evaluation was the same. For example, HTG village belongs to Match-L. HTG village located at Mao County and closed to a debris flow gully. Due to the high relief degree of land surface, the farmland was limited. The objective assessment reported it was not suitable for human activity while the subjective evaluation was inferior due to the limited land and effect of mountain hazards.

The second indicator was L-H, it meant that the differences between objective and subjective evaluation was significant. From the objective aspect, the region was suitable for human activity, however, from the subjective aspect, the human-environment relationship was not the same with the objective evaluation. This region needs to pay more attention in order to find out why the subjective evaluation was not as good as objective evaluation and the way to prompt the human-environment relationship. It was worth noting that the socio-economic and demographic variables also play a role in subjective evaluation, such as the match between an individual's talents and the corresponding needs of the environment or the sense of fulfillment and beauty in front of a certain environment [14]. Therefore, the key of human-environment coordination in these areas was speculating the reasons for low subjective assessment considering the socio-economic and demographic variables. For example, YGM village and XMX village belonged to $\mathrm{L}-\mathrm{H}$. Through the analysis of the socio-economic and demographic variables, as well as the characteristic of the villages, it showed that the development of industry was the main reason for low subjective evaluation. This indicates that the human-environment relationship in this region had a tendency to deteriorate, which needed special attention.

The third indicator was H-L. From the objective perspective, the region was not suitable for human activity; however, from the subjective perspective, villagers were satisfied with the environment and thought that the human-environment harmonious. For example, the MD value of MT village and MK village was low while the objective evaluation was inferior or general. This result indicates that the appropriate development was more important for human-environment coordination. Tourism was one of the green developments, even though the objective evaluation of MT village and MK village was relatively low, the development of tourism promoted the human-environment coordination. Therefore, the subjective evaluation was high. The key of human-environment coordination in these areas was analyzing the development model and providing reference models for other regions.

Therefore, the Match- $\mathrm{L}$, as well as the $\mathrm{L}-\mathrm{H}$ and $\mathrm{H}-\mathrm{L}$, were more comprehensive indicators to evaluate the human-environment relationship to effectively guide and coordinate the human-environment relationship.

\subsection{As the Subjective Evaluation Was Based on Individual Comprehensive Tradeoffs, the Evaluation Combining the Objective Assessment Was More Accurate}

Drawing on relevant theories of cognitive psychology, environmental satisfaction is necessarily purposive; i.e., it depends on people's goals and focus [21,22]. In other words, human cognition 
concerning the environment is based on the objective environment and influenced by the comprehensive effect of subjective factors, such as their own environmental protection consciousness, or personal benefit to come from development, family income, source of livelihood, etc. Evaluating human environment only from the subjective perspective would be biased. Therefore, the framework provided in this study which combines the objective and subjective evaluation was more accurate for exploring the human-environment relationship. The results of this study confirmed this. Known from the case analysis, most residents in XMX village thought (in the subjective evaluation) that the human-environment relationship was depleted by industry development. However, the few residents working in the factory whose income from the enterprise was their main source of household income thought the human-environment congruity was general.

- 'I worked in the factory since its construction. The effect of this factory on the environment was small. The gas discharged from the factory was treated and did not pollute the environment.' one of the residents who worked in the factory said [23].

GK village was a relocation village due to hydropower construction and disaster avoidance projects. Half of the new village was the hydropower construction relocation (we called it village A) while the other was disaster avoidance relocation (we called it village B). The government unified planning and construction of the new village. Compared to the original village, the living conditions in the new village were much better; however, attitudes to the environment were obviously different among residents. Most of the residents from village A thought the human-environment congruity was harmonious or general while a large number of residents from village B thought the human-environment congruity was general or inferior. The reason for this difference was that the farmland of village B remained in the original village so residents had to abandon cultivated land because of the walking distance. More importantly, due to a lack of skills, most residents could not find a job other than farming. The attitudes to the environment were the result of the overall balance of advantages and disadvantages for individuals.

- 'Our farmland was not relocated to this village. Because of the distance, I cannot get to the original village on foot. I must go back by motorcar or bus to farm. It takes 100 minutes to go back and forth. So I had to give up farming. However, I don't know any other work except farming. I want to move back to the original village, even if there is a threat of disaster,' one of the residents of village B said [23].

Village AX gives empirical evidence about how environmental protection consciousness affects the perception of the environment. AX village was close to a tourism park famous for its skiing. The construction of the ski resort had an impact on the surrounding environment, such as reducing grassland. Villagers who did not care about environmental protection were satisfied with the human-environmental relationship, while villagers who paid attention to environmental protection thought the human-environmental relationship worsened with the construction of the ski resort. As a result of the subjective evaluation, AX was balanced (the proportion of each type, harmonious, general, and inferior, were equal).

4.3. Environmental Conditions Are the Basis, and Human Activities Are the Key Factors for the Coordination of Human-Environment Relationship, so the Matrix Put Forward in this Study Is Necessary for Finding the Cause of Human-Environment Incongruity

The human-environment relationship is bidirectional, as human attitudes and behavior to nature are at the root of environmental change, while changes in the environment affect human attitudes and behavior. Furthermore, with the change of human's cognition and utilization ability of environment, the influence of environment also changes accordingly. Therefore, actually in the human-environment relationship, "human" is in the active position. Whether the human-environment relationship is harmonious or contradictory depends more on human cognition and activities. As a 
result, it is necessary for finding the cause of human-environment incongruity to combine subjective cognition. The case study confirmed this conclusion. Combined objective and subjective assessments found out the following: (1) Improper industry development in an area of human-environment congruity caused deterioration in the human-environment relationship; (2) tourism development would promote coordination of the human-environment relationship in regions with relatively low human-environment congruity.

Firstly, the situation seen in the XMX and YGM village show that even in areas where human-environment relationship are harmonious, improper industry development was not conducive to human-environment relationship [23]. These two villages are located in Wenchuan County, north of the upper Minjiang River basin. From the objective evaluation, the ecological vulnerability of XMX and YGM village was low. Furthermore, the location advantage of these two villages was obvious-close to Chengdu, the capital of Sichuan province. Furthermore, it was near the highway exit, so transportation was very convenient and the government made the main core area for economic development in the upper Minjiang River basin. Industrial parks were laid out here. From the objective viewpoint, human-environment congruity should have been harmonious (intense human activity in an area with low ecological vulnerability). However, the MD indicator show that the MD values of YGM village and $X M X$ village were very low. The objective evaluation of YGM village and XMX village was harmonious while the subjective evaluation of these two villages was inferior. Due to the cement plant, the air was polluted and the vegetation was affected, turning yellow. Villagers thought the environment was no longer suitable for living.

- 'In the past, the environment of the village was very good; because of the construction of the factory, the air was not good, there was often a pungent smell, the leaves were smoked yellow, and some of them were directly dry,' an old villager in the XMX village said.

Secondly the MK village, MT village, and QD village provided empirical evidence that tourism development would promote coordination of the human-environment relationship in regions with relatively low human-environment congruity. From the objective evaluation, human-environment congruity in these three villages was low or general, due to their low ecological vulnerability with high human activity intensity. Known from the HD indicator, the HD value of MT village, MK village and QD village was $0.88,0.68$, and 0.55 , respectively, meaning the subjective evaluation of human-environment congruity was much higher than the objective evaluation. Of the villages where the objective evaluation was inferior or general, only these three villages developed tourism. The leading industry of MT village was tourism, while it was agriculture and tourism in MK and QD villages.

Tourism development prompted human-environment congruity in these three villages. On the one hand, villagers paid more attention to environmental protection in order to increase the attractiveness of the village and promote tourism development. On the other hand, because of the tourism development, villagers could stay home instead of going out to work. As a result, from the subjective viewpoint, people felt that the human-environment relationship was harmonious. It is worth noting that the better the tourism development, the higher the subjective evaluation of human-environment congruity was. Tourism in MT was operated by a company, MK village was a spontaneous tourism village, and the government guided QD village to develop tourism. There was little difference between these three villages. MT was already a 4A scenic spot, relying on attractions to bring in visitors. MK focused on experiential tourism, relying on fruit picking. QD was a relocation village, built into a cultural experience base and relying on an experience of the life of a Tibetan family. As a result, among these three villages, MT village had the best tourism development, followed by MK village and QD village.

\section{Conclusions}

Our exploration extends the existing literature, providing a framework to evaluate the human-environment relationship. This framework included two key parts, quantitative analysis and qualitative analysis. The quantitative analysis put forward two indicators, as well as four situations to 
quantify the difference between objective assessment and subjective evaluation of human-environment relationship. The qualitative analysis was conducted to get the regional difference among the areas with different human-environment relationships, and then through summarizing the reasons for regional differences, the cause about human-environment incongruency was identified. The framework was verified and can be applied to other regions.

However, there were some limitations of this study. Firstly, the socio-economic and demographic variables also play a role in subjective evaluation, but this study did not pay attention to analyzing the influence of personal characteristics on the differences between the objective assessment and subjective evaluation, so the next step is to explain the coupled mechanism of personal characters and regional characters that led the difference between objective assessment and subjective evaluation through the HLM model. Secondly, considering the application of the model, there were only two parameters to assess the human impact: Settlement activity intensity and road construction intensity. The settlement activity takes into account population density, as well as farmland. However, as reported in the literature [24-26], more human activities should be considered. Therefore, the next step is to supplement the model parameters.

Supplementary Materials: Supplementary materials can be accessed at http:/www.mdpi.com/2071-1050/12/1/ $167 / \mathrm{s} 1$.

Author Contributions: Y.L., W.D., L.P. and Y.L. conceived and designed the research, Y.L., W.D. collected and analyzed the data, Y.L. wrote the paper, L.P. provided and revised suggestions for the paper. All authors have read and agreed to the published version of the manuscript.

Funding: The National Natural Science Foundation of China (Grant No. 41801140) and CAS "light of west China" program.

Acknowledgments: We would like to thank four anonymous reviewers for constructive comments leading to significant improvement on this article from its original form. We thank all funding support from The National Natural Science Foundation of China (Grant No. 41801140) and CAS "light of west China" program. Any opinions, findings, and conclusions or recommendations expressed in this material are those of the author(s) and do not necessarily reflect the views of the sponsoring parties mentioned above.

Conflicts of Interest: The authors declare no conflict of interest.

\section{References}

1. Cao, G.; Lei, J.; Jin, F. The classification and assessment of vulnerability of man-land system of oasis city in arid area. Front. Earth Sci. 2013, 7, 406-416.

2. Alessa, L.N.; Kliskey, A.A.; Brown, G. Social-ecological hotspots mapping: A spatial approach for identifying coupled social-ecological space. Landsc. Urban Plan. 2008, 85, 27-39. [CrossRef]

3. Hamann, M.; Biggs, R.; Reyers, B. Mapping social-ecological systems: Identifying 'green-loop' and 'red-loop' dynamics based on characteristic bundles of ecosystem service use. Glob. Environ. Chang. 2015, 34, 218-226. [CrossRef]

4. Uzzell, D.; Pol, E.; Badenas, D. Place Identification, Social Cohesion, and Enviornmental Sustainability. Environ. Behav. 2002, 34, 26-53. [CrossRef]

5. Taylor, P.D. Identity and the Natural Environment: The Psychological Significance of Nature; Clayton, S., Opotow, S., Eds.; The MIT Press: Cambridge, MA, USA, 2003.

6. Hinds, J.; Sparks, P. Engaging with the natural environment: The role of affective connection and identity. J. Environ. Psychol. 2008, 28, 109-120. [CrossRef]

7. Perrin, J.L.; Benassi, V.A. The connectedness to nature scale: A measure of emotional connection to nature? J. Environ. Psychol. 2009, 29, 434-440. [CrossRef]

8. Gosling, E.; Williams, K.J.H. Connectedness to nature, place attachment and conservation behaviour: Testing connectedness theory among farmers. J. Environ. Psychol. 2010, 30, 298-304. [CrossRef]

9. Restall, B.; Conrad, E. A literature review of connectedness to nature and its potential for environmental management. J. Environ. Manag. 2015, 159, 264-278. [CrossRef]

10. Lange, F.; Steinke, A.; Dewitte, S. The Pro-Environmental Behavior Task: A laboratory measure of actual pro-environmental behavior. J. Environ. Psychol. 2018, 56, 46-54. [CrossRef] 
11. Whitmarsh, L.; O'Neill, S. Green identity, green living? The role of pro-environmental self-identity in determining consistency across diverse pro-environmental behaviours. J. Environ. Psychol. 2010, 30, 305-314. [CrossRef]

12. Davis, J.L.; Green, J.D.; Reed, A. Interdependence with the environment: Commitment, interconnectedness, and environmental behavior. J. Environ. Psychol. 2009, 29, 173-180. [CrossRef]

13. Grankvist, G.; Dahlstrand, U.; Biel, A. The Impact of Environmental Labelling on Consumer Preference: Negative vs. Positive Labels. J. Consum. Policy 2004, 27, 213-230. [CrossRef]

14. Muchinsky, P.M.; Monahan, C.J. What is person-environment congruence? Supplementary versus complementary models of fit. J. Vocat. Behav. 1987, 31, 268-277. [CrossRef]

15. Marans, R.W. Understanding environmental quality through quality of life studies: The 2001 DAS and its use of subjective and objective indicators. Landsc. Urban Plan 2003, 65, 73-83. [CrossRef]

16. Bonnes, M.; Uzzell, D.; Carrus, G.; Kelay, T. Inhabitants' and Experts' Assessments of Environmental Quality for Urban Sustainability. J. Soc. Issues 2007, 63, 59-78. [CrossRef]

17. Horelli, L. Environmental human-friendliness as a contextual determinant for quality of life. Eur. Rev. Appl. Psychol. 2006, 56, 15-22. [CrossRef]

18. Moser, G. Quality of life and sustainability: Toward person-environment congruity. J. Environ. Psychol. 2009, 29, 351-357. [CrossRef]

19. Rodella, I.; Corbau, C. Linking scenery and users' perception analysis of Italian beaches (case studies in Veneto, Emilia-Romagna and Basilicata regions). Ocean Coast. Manag. 2020, 183, 104992. [CrossRef]

20. The Sixth Census of China. Available online: http://www.stats.gov.cn/tjsj/pcsj/rkpc/6rp/indexch.htm (accessed on 24 December 2019).

21. Burns, A.E.; Galbraith, J.K. On the quality of life. Mon. Labor Rev. 1971, 94, 76-77.

22. Diener, E.; Suh, E.M.; Lucas, R.E.; Smith, H.L. Subjective Well-Being: Three Decades of Progress. Psychol. Bull. 1999, 125, 276-302. [CrossRef]

23. Poll, R.; Stellato, R.; Kruize, H.; Heisterkamp, S. Residential satisfaction and annoyance in residents living near industrial estates. Epidemiology 2005, 16, S28. [CrossRef]

24. Corbau, C.; Zambello, E.; Rodella, I.; Utizi, K.; Nardin, W.; Simeoni, U. Quantifying the impacts of the human activities on the evolution of Po delta territory during the last 120 years. J. Environ. Manag. 2019, 232, 702-712. [CrossRef]

25. Parravicini, V.; Rovere, A.; Vassallo, P.; Micheli, F.; Montefalcone, M.; Morri, C.; Paoli, C.; Albertelli, G.; Fabiano, M.; Bianchi, C.N. Understanding relationships between conflicting human uses and coastal ecosystems status: A geospatial modeling approach. Ecol. Indic. 2012, 19, 253-263. [CrossRef]

26. Ye, Y.; Bryan, B.A.; Zhang, J.; Connor, J.D.; Chen, L.; Qin, Z.; He, M. Changes in land-use and ecosystem services in the Guangzhou-Foshan Metropolitan Area, China from 1990 to 2010: Implications for sustainability under rapid urbanization. Ecol. Indic. 2018, 93, 930-941. [CrossRef] 